\title{
George Sand et ses personnages. 1804-2004, sous la direction de DOMINIQUE LAPORTE et DAVID POWELL
}

\section{Mertine Watrelot}

\section{(2) OpenEdition}

\section{Journals}

\section{Édition électronique}

URL : http://journals.openedition.org/studifrancesi/30511

DOI : 10.4000/studifrancesi.30511

ISSN : 2427-5856

\section{Éditeur}

Rosenberg \& Sellier

\section{Édition imprimée}

Date de publication : 1 avril 2006

Pagination : 176-177

ISSN : 0039-2944

\section{Référence électronique}

Mertine Watrelot, «George Sand et ses personnages. 1804-2004, sous la direction de DOMINIQUE LAPORTE et DAVID POWELL », Studi Francesi [En ligne], 148 (XLX | I) | 2006, mis en ligne le 30 novembre 2015, consulté le 21 avril 2021. URL : http://journals.openedition.org/studifrancesi/30511 ; DOI : https://doi.org/ 10.4000/studifrancesi.30511

Ce document a été généré automatiquement le 21 avril 2021.

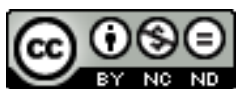

Studi Francesi è distribuita con Licenza Creative Commons Attribuzione - Non commerciale - Non opere derivate 4.0 Internazionale. 


\title{
George Sand et ses personnages. 1804-2004, sous la direction de DOMINIQUE LAPORTE et DAVID POWELL
}

\author{
Mertine Watrelot
}

\section{RÉFÉRENCE}

AA. VV. George Sand et ses personnages. 1804-2004, sous la direction de DOMINIQUE LAPORTE et DAVID POWELL, in « Études littéraires », t. XXXV, n 2-3, été-automne 2003, pp. 170.

1 Ce numéro de la grande revue canadienne «Études littéraires » entièrement consacré à George Sand et ses personnages réunit des spécialistes américains et canadiens de l'œuvre de Sand se penchant sur l'étude, quelque peu oubliée depuis les études sémiotiques des années soixante-dix, des divers dispositifs mis en œuvre par un auteur pour construire ou remettre en question les personnages de ses romans. La panoplie des personnages, examinée par Anna Szabo, en 1991, avait mis en évidence que, dans la fiction sandienne, le personnage est plus important que l'action, le héros étant toujours d'une moralité supérieure à celle des autres protagonistes de la fiction. Comme l'écrivent, dans leur présentation, D. LAPORTE et D. POWELL (p. 1-13) il s'agit cette fois d'interroger la finalité même de la praxis sandienne trop souvent rattachée au roman idéaliste.

2 Anne MAC-CALL-SAINT-SAENS entame la réflexion par une belle étude sur la manière d'«Écrire la lecture expérimentale du Secrétaire intime au Marquis de Villemer " (pp.13-26). Puisque, dans le lexique sandien, «lire» désigne tout acte d'interprétation, les personnages de ses romans sont tous lecteurs - au moins du cœur d'autrui - tandis que les deux oeuvres retenues explorent le pouvoir des lecteurs et tentent de le définir. Par un jeu de personnages qui lisent plume à la main, Sand organise, en visionnaire, une démonstration expérimentale du pouvoir bénéfique de la lecture comme activité créatrice et acte fondateur d'une société, à venir, de type communautaire. Françoise MASSARDIER-KENNEY trouve en Valvèdre (pp. 29-38) un exemple 
frappant de la construction du personnage comme notion problématique : une étude des appellatifs du roman montrant l'incertitude des frontières entre l'identité de chacun des personnages, des perturbations s'ensuivent sur le processus d'identification du lecteur aux héros. Yvette Bozon-SCALZITTI offre par l'étude du « Personnage de sangfroid» (pp. 39-59) un stimulant rapprochement entre Corneille et Sand en montrant que le nouveau type de personnage - bon, fraternel, moral - voulu par Sand pour incarner le socialisme évangélique ne parvient pas à abjurer la volonté de puissance du héros cornélien. Or, le personnage de sang-froid, par l'incarnation d'une des caractéristiques majeures du roman sandien, à savoir son intellectualisme et sa facticité, pourrait bien être le personnage sandien par excellence.

Dominique LAPORTE (pp. 61-69) étudie les différentes éditions d'Indiana pour interroger l'interdiscursivité du personnel romanesque aux fins de produire moins des effetspersonnes que des effets de discours propres à trahir la fictionnalité du roman. Par une étude du même roman, Pratima PRASAD se penche sur la réécriture du couple Paul et Virginie transposé par Sand sur deux personnages féminins, créoles mais distincts de race, Indiana et Noun, afin de discerner la compréhension qu'avait la romancière des implications sociales et culturelles de l'histoire coloniale (pp. 71-85).

4 Suit un très bel article d'Isabelle Hoog NAGINSKI (pp. 87-105) qui montre avec une maîtrise saisissante la complexité et la richesse audacieuse du personnage de Lélia. Décrite par Sand comme une héroïne «tout à fait impossible... à force de vouloir être abstraite et symbolique ", Lélia va être promise à un destin littéraire polyvalent et fructueux par les réécritures qu'elle va susciter. I. Naginski nous donne comme exemple de cette ambivalente postérité Camille Maupin, imaginée par Balzac, et Bérangère de Gesvres, voulue par Barbey d'Aurevilly. Survivant à toutes les critiques et les insultes, Lélia va se poser, jusqu'à nos jours, en modèle pour toute une série de futures héroïnes.

5 Vouloir étudier les personnages de Sand empêche d'ignorer l'écriture dramatique, souvent négligée sans être négligeable pour autant, de cette romancière. De façon tout à fait éclairante et bienvenue, Shira MALKIN nous invite à une réflexion sur la mise en scène du tableau pathétique dans le roman Adriani (pp. 107-21), daté de 1853. Alors que Sand écrit de front pour le roman et pour le théâtre, elle emploie ici les techniques du tableau et du coup de théâtre héritées du drame bourgeois tout en en problématisant les enjeux idéologiques. En état de crise, ses personnages, féminins notamment, partent en quête d'un auditoire actif pour se construire en se racontant et dépasser le pathétique voulu par le genre.

6 Il revient à David Powell de clore le volume par une étude synthétique, touffue, passionnante du « Mentir narratif. Personnages et narrateurs mensongers chez Sand » (pp. 123-39). Au-delà du mentir du narrateur il s'agit, à travers Jacques et de Ma Soeur Jeanne, d'interroger les effets du mentir des personnages, qui se mentent autant à euxmêmes qu'aux autres personnages, afin de voir comment ces narrateurs malmènent le lecteur par des menteries devenues parties intégrantes de la structure narrative comme de la thématique de ces deux romans. La maîtrise de la technique narratologique du mensonge permet à Sand une fine étude de la condition humaine et permet à David Powell une réflexion moins esthétique que philosophique sur la relation de l'art à la vérité.

7 Ce volume recense donc de riches et très intéressantes réflexions qui ne peuvent prétendre à l'exhaustivité, bien sûr. On peut regretter l'absence d'étude sur les 
personnages secondaires qui, souvent chez Sand, atteignent au statut de types, se sentir frustré par le silence sur le renouveau du roman de comédiens auquel Sand contribue. La citation « Née romancier, je fais des romans » mise en exergue de ce dossier imposait d'étudier le personnel des formes romanesques, on ne peut que féliciter l'équipe d'avoir attiré notre attention sur des romans moins connus que Lélia ou Indiana, sans exclure pour autant ces titres de leur corpus. Les articles visent à repositionner Sand dans l'horizon actuel de lectures, critiques ou non, qui fera d'elle un auteur majeur. L'originalité et la fécondité des sujets choisis est donc à souligner, la qualité de ce numéro à saluer. 